\title{
A SISTEMATIZAÇÃO DA PREVIDÊNCIA PRIVADA BRASILEIRA E UMA ABORDAGEM DE ASPECTOS PREVIDENCIÁRIOS NO EXTERIOR
}

\author{
Arthur Bragança de Vasconcellos Weintraub \\ Mestre em Direito Previdenciário pela Faculdade de Direito da \\ Universidade de São Paulo
}

\begin{abstract}
Resumo:
O presente estudo tem por escopo apresentar umı breve sistematização da Previdência Privada brasileira, esboçando uma abordagem de aspectos previdenciários da Itália, do Chile e dos EUA.
\end{abstract}

\begin{abstract}
:
The present essay is about a brief systemisation of Brazil's private retirement plans, drafting an approach of social security in Italy, Chile and USA.
\end{abstract}

Unitermos: Previdência Privada brasileira; aspectos previdenciários da Itália, do Chile e dos EUA.

Sumário:

1. Sistematização da Previdência Privada brasileira;

2. A Previdência Complementar na Itália;

3. Previdência Social Chilena;

4. Os 401(k) americanos;

5. Bibliografia

\section{Sistematização da Previdência Privada brasileira}

Até a instituição da Previdência Pública, em 23 de janeiro de 1923, a Previdência Privada brasileira não podia ser tida como complementar, haja vista a inexistência de uma previdência principal básica. 
Não houve uma sistematização legislativa, até 1977, que organizasse essas entidades privadas, que acabaram se submetendo ao Código Civil ou a outras normas comerciais ou de seguro privado.

A Previdência Complementar só veio a ser regrada com o surgimento da Lei n. 6.435/77. Essa Lei foi regulamentada pelos Decretos n. 81.240/78 (entidades fechadas) e n. 81.402/78 (entidades abertas), além de outras resoluções da Secretaria de Previdência Complementar (SPC) e da Superintendência de Seguros Privados (Susep).

Para os efeitos da Lei n. 6.435/77, as entidades de Previdência Privada são aquelas que têm por objeto instituir planos privados de concessão de pecúlios ou de rendas, de benefícios complementares ou assemelhados aos da Previdência Social, mediante contribuição de seus participantes, dos respectivos empregadores ou de ambos. Considera-se participante o associado, segurado ou beneficiário incluído nos planos privados.

A Lei n. $6.435 / 77$, em seu art. $4^{\circ}$ classifica as entidades de Previdência Privada de acordo com a relação entre a entidade e os participantes dos planos de benefícios:

"I - a) fechadas, quando acessíveis exclusivamente aos empregados de uma só empresa ou de um grupo de empresas, as quais, para os efeitos desta Lei, serão denominadas patrocinadoras;

b) abertas, as demais"

Em relação aos objetivos, a classificação legal se faz entre entidades de fins lucrativos e entidades sem fins lucrativos. Pela Lei n. 6.435/77 (art. $\left.4^{\circ}, 1^{\circ}\right)$, as entidades fechadas não poderão ter fins lucrativos. São equiparáveis aos empregados de empresas patrocinadoras os seus gerentes, os diretores e conselheiros ocupantes de cargos eletivos, bem como os empregados e respectivos dirigentes de fundações ou outras entidades de natureza autônoma, organizadas pelas patrocinadoras (Lei n. 6.435/ 77 , art. $\left.4^{\circ}, 2^{\circ}\right)$.

As entidades de Previdência Privada (art. $5^{\circ}$ da Lei n. 6.435/77) serão organizadas como:

I - sociedades anônimas, quando tiverem fins lucrativos;

II sociedades civis ou fundações, quando sem fins lucrativos. 
A Lei n. $6.435 / 77$ (art. $6^{\circ}$ ), não considera atividade de Previdência Privada a simples instituição, no âmbito limitado de uma empresa, de uma fundação ou de outras entidades de natureza autônoma, de pecúlio por morte, de pequeno valor, desde que administrado exclusivamente, sob a forma de rateio entre os participantes.

Finalmente, a Lei n. $6.435 / 77$ (art. $7^{\circ}$ ) dispõe que as entidades abertas integram-se ao Sistema Nacional de Seguros Privados, e serão reguladas pelas disposições da referida Lei e, no que couber, pela legislação aplicável às entidades de seguro privado (art. 10).

A terminologia envolvendo Previdência Complementar foi influenciada pelos private pension funds norte-americanos. Isso não impediu a adoção no Brasil de um jargão próprio de muitos institutos.

É importante diferenciar a Previdência Privada, a Previdência Oficial e o Seguro Privado. A Previdência Oficial diz respeito ao Regime Geral da Previdência Social (RGPS). O Seguro Privado possui até uma existência paralela à Previdência Privada, como nos caso das entidades abertas de previdência complementar que mantêm, além dos planos previdenciários privados, planos de seguro de vida ou contra acidentes automobilísticos.

Algumas denominações utilizadas na Previdência Pública não são aplicadas na Previdência Privada. Contingência da Previdência Pública tem sentido de risco da Previdência Privada (que é o fato da vida que enseja a concessão de algum benefício ou auxílio). E a contribuição previdenciária, que tem a característica de tributo, na Previdência Privada se baseia no prêmio pago a seguradoras.

Todavia, não há que se confundir Previdência Privada com seguro privado, estrito senso, mesmo porque a própria palavra indenização, muito empregada no seguro privado, não é utilizada no contexto de previdência.

Alguns nuances terminológicos existem, inclusive entre as entidades abertas de Previdência Privada e as entidades fechadas de Previdência Privada.

Não-obstante, grosso modo, todos aqueles que sejam contratantes de planos de Previdência Privada serem vistos como segurados, o enquadramento mais técnico do segurado no segmento de Previdência Privada é o de participante (denominação mais preponderante nas entidades fechadas).

O regime de Previdência Privada é previsto pelo art. 202 da Constituição, previsão derivada da Emenda Constitucional n. 20, de 15 de dezembro de 1998. De caráter complementar e organizada de forma autônoma em relação ao Regime Geral de Previdência Social, a Previdência Privada é facultativa. 
A Previdência Privada está submetida à Lei n. 6.435/77 (que sofreu alterações com a Lei n. 6.462/77, com o Decreto-Lei n. 2.053/83 e com a Lei n. 8.020/ 90), sendo que os arts. $8 / 33$ referem-se à Previdência Privada aberta, e os arts. 34/50 referem-se à fechada. Outra norma significativa consiste no Decreto-Lei n. 73/66, regulamentado pelo Decreto n. 60.459/67, e alterado pelos Decretos-Leis n. 168/67 e n. 296/67. O Decreto-Lei n. 73/66, que em seu art. $3^{\circ}$ parágrafo único, dentro das disposições sobre o Sistema Nacional de Seguros Privados, exclui taxativamente o Regime Geral da Previdência Social de suas previsões.

A Lei n. 6.435/77 foi regulada por dois Decretos: Decreto n. 81.240/78 (Regulamento da Previdência fechada); Decreto n. 81.402/78 (Regulamento da Previdência aberta). Prevê a Lei n. 6.435/77, em seu art. 10, que: "as entidades abertas serão reguladas pelas disposições da presente lei e, no que couber, pela legislação aplicável às entidades de seguro privado" Aplica-se às entidades abertas com fins lucrativos o disposto no art. 25 da Lei n. 4.595/64, com a nova redação dada pelo art. 1 da Lei n. 5.710/71.

Sérgio Pinto Martins (Direito da Seguridade Social, 2000, p. 296) caracteriza a Previdência Privada Complementar, seja ela aberta ou fechada, como "significativo método de proteção social, com a complementação da previdência oficial" (grifos nossos). Esse caráter protetivo enaltece o âmbito privado da Previdência, sem sustar sua base econômica não-estatal.

As entidades abertas de Previdência Privada são, normalmente, companhias seguradoras ou sociedades anônimas que oferecem planos de previdência, sob a fiscalização da Susep (Superintendência de Seguros Privados). Os planos de Previdência Privada aberta são muito mais flexíveis do que os planos de Previdência Privada fechada, apesar do caráter contratual de ambos.

As entidades de Previdência fechada (organizadas, grosso modo, na forma de sociedades civis ou de fundações) são conhecidas como "fundos de pensão", criados entre uma ou mais empresas de um mesmo grupo econômico, onde os beneficiários são seus funcionários. Na Previdência Privada aberta, normalmente, o contratante é chamado de segurado, enquanto na Previdência Privada fechada o contratante é chamado de participante.

No que tange às contribuições do empregador, os benefícios que as condições contratuais previstas no estatuto, regulamentos e planos de beneficios das entidades de Previdência Privada, não integram o contrato de trabalho dos participantes.

A entidade empregadora pode contribuir com até $50 \%$ em relação à 
contribuição do funcionário, sendo denominada "patrocinadora" Esse limite é, inclusive, ressaltado para as entidades ligadas ao Estado, pelo $\S 3^{\circ}$, do art. 202, da CF/ 88, que dispõe:

"É vedado o aporte de recursos a entidades de Previdência Privada pela União, Estados, Distrito Federal e Municípios, suas autarquias, fundações, empresas públicas, sociedades de economia mista e outras entidades públicas, salvo na qualidade de patrocinador, situação na qual, em hipótese alguma, sua contribuição normal poderá exceder a do segurado."

De acordo com determinação do art. 43 da Lei n. 6.435/77, a cada balanço, os planos de benefícios deverão ser apreciados por atuário ou instituto habilitado. $\mathrm{O}$ Instituto Brasileiro de Atuária (IBA) é o órgão responsável pela apuração da responsabilidade dos profissionais dessa área, em caráter administrativo.

Os percalços enfrentados no quadro da Previdência Privada são semelhantes aos da Previdência estatal, porém não são idênticos. Existe certa independência científica no estudo da matéria, além de uma submissão ao Direito Privado.

\section{A Previdência Complementar na Itália}

Nesse ponto do trabalho, é significativo apresentar um breve apanhado 'da situação da Previdência Privada no Exterior, para que tenhamos uma visão previdenciária de outros países.

Os fundos de previdência complementar foram instituídos na Itália por uma lei de 1993, que pouco efeito causou, já que somente $5 \%$ do total de trabalhadores italianos fazem parte desses fundos. Não-obstante, na Alemanha, esse percentual vai para 46\%; na Grã-Bretanha, 48\%; e na Irlanda, 40\% dos trabalhadores. Outros países têm uma adesão pouco menor, mas ainda assim expressiva, tal como a Bélgica (31\%), Portugal e Espanha (ambos com 15\%) (Fonte: Corriere della Sera, 01.09.00, p. 10).

O lema da reforma da previdência italiana é "anziani, siate meno egoisti" (idosos, sejam menos egoístas). A idéia do atual Governo é a passagem imediata do regime de repartição para o regime de capitalização (programa Forza Italia). A manutenção do regime de repartição em vigor na Itália acarreta uma marginalização da previdência pública, pois diante do envelhecimento populacional e baixa taxa de fecundidade, os recursos para pagamento de aposentadorias vão escasseando, com uma tendência a garantir exclusivamente um sustento mínimo ao aposentado. $O$ principal argumento governamental paira na assertiva de que sem reforma, a previdência não 
tutelará os mais jovens (quando esses se aposentarem), dentro do atual regime de repartição. Contudo, a previdência complementar na Itália ainda está num estágio embrionário (Fonte: Corriere della Sera, 01.09.00, p. 10).

É interessante notar que em nenhum país da União Européia, o homem se aposenta com menos de 65 anos, a não ser proporcionalmente (e mesmo assim, França, Grã-Bretanha, e Holanda não permitem a aposentadoria proporcional). Para a mulher, o limite é de 60 anos para a aposentadoria, sendo que na maioria dos países da UE não há diferenças entre limites etários na aposentadoria de homens e mulheres (Fonte: Banco Mundial).

A Itália possui a idade média de aposentadoria mais baixa da UE: 61,4 anos. Em outros países europeus essa idade média é mais elevada, como na Espanha $(65,3)$, na Holanda $(65)$, e na Alemanha $(62,6)$. Na Itália existe a pensão por velhice (pensioni di anzianitá), semelhante ao nosso amparo social-LOAS, que não existe na Alemanha ou na França, por exemplo. E a despesa pública para aposentadorias na Itália absolve $15 \%$ do PIB. (Fonte: Corriere della Sera, 01.09.00, p.10).

\section{Previdência Social chilena}

Pela razão das citações da doutrina especializada sobre a Previdência chilena, é relevante à presente pesquisa um sintético apanhado desse tema.

O atual sistema de Previdência Social chileno entrou em vigor em 1981. Desde então, todos aqueles que ingressaram no mercado de trabalho passaram a contribuir compulsoriamente com $10 \%$ de seus salários brutos em fundos de pensão privados de sua eleição.

Em 1 de maio de 1981, entrou em vigor no Chile o Decreto-Lei n. 3.500, que reformou o Sistema de Pensões existente no país, uniformizados os distintos regimes previdenciários (dos trabalhadores do setor público e privado). A legislação chilena passou a estabelecer que os trabalhadores que estavam no antigo sistema poderiam optar por incorporar-se ao novo ou manterem-se no antigo (incorporación voluntaria).

Desde 1981, o sistema previdenciário chileno está embasado no regime de capitalização, onde cada segurado possui uma conta individual e pessoal onde deposita suas aplicações previdenciárias obrigatórias com o objetivo de formar um capital, fruto dos aportes financeiros e dos juros gerados. Após o cumprimento dos requisitos exigidos pelo sistema, o capital aplicado é devolvido ao segurado, ou aos seus sobreviventes, na modalidade de benefício previdenciário (pensión previsional). 
O sistema previdenciário do Chile é administrado por entidades de Previdência Privada. Nesse contexto, o trabalhador possui a liberdade de escolher livremente a entidade à qual se filiar, podendo mudar de uma administradora para outra, quando achar conveniente aos seus interesses (é a chamada portabilidade, que não existe no Brasil, mas já é objeto de proposta de mudança legislativa).

O Estado chileno, perante o atual sistema previdenciário, possui um papel fundamentalmente controlador e a subsidiário, significando a existência de um controle estrito sobre as Administradoras de Fundos de Pensão. A lei chilena permite às administradoras efetuar o chamado resseguro (ou contra-seguro), para que os benefícios sejam honrados. Essas administradoras são fiscalizadas pela Superintendencia de Administradoras de Fondos de Pensiones. Por outro lado, cabe ao Governo assegurar uma rentabilidade mínima das aplicações nos fundos previdenciários dos trabalhadores, além de assegurar aos filiados ao sistema uma aposentadoria mínima, quando os fundos acumulados por cada um não forem suficientes. Isto é, caso não haja uma rentabilidade mínima pré-estabelecida dos recursos previdenciários aplicados, o Estado complementa a diferença.

Não-obstante, mesmo que o trabalhador possua várias atividades, só poderá haver filiação a uma Administradora de Fundos. A filiação ao sistema previdenciário chileno é obrigatória para os trabalhadores que começaram a trabalhar a partir de $1^{\circ}$ de janeiro de 1983.

Os trabalhadores que se filiaram ao fundo de Previdência Privada receberam um bônus reajustado correspondente às suas contribuições do antigo sistema, que foi depositado na administradora de suas preferências, resgatável de forma diferida com a saida do mercado de trabalho. O sistema é gerido pelas Administradoras de Fundos de Pensão, conhecida pela sigla AFP.

O atual sistema privado de Previdência Social do Chile começou com a adesão de $25 \%$ de força de trabalho chilena. Hoje, $93 \%$ do total da massa de trabalhadores contribui em relação a 22 fundos privados que competem entre si. O patrimônio destas instituições chega hoje a US\$ 22,2 bilhões, alcançando $41 \%$ do PIB que é de ordem aproximada de US\$ 54 bilhões (Fonte: Escritório Comercial do Chile no Brasil).

Caso o trabalhador não se sinta satisfeito, há total liberdade de troca de fundo (portabilidade), possibilitando aos segurados um controle da eficiência do sistema. O Governo chileno garante aposentadoria mínima de US\$130, caso tenha havido por parte do trabalhador contribuições para o sistema privado por no mínimo vinte anos. 
Sem a contribuição mínima, pode haver complementação pelo Governo (uma forma de assistência social).

Porém, há deméritos quanto a esse sistema chileno. Existe o problema do desconto para depósitos no fundo de pensão, sem o devido recolhimento (apropriação indébita). Entretanto, a maior crítica consiste na vulnerabilidade do sistema privado diante da vinculação mercados de capitais do Chile, cuja estrutura pode ser abalada. Havendo uma crise no mercado financeiro, com a quebra dos fundos de pensão, o Tesouro Nacional chileno terá de arcar com o prejuízo de todos os segurados, por meio de intervenção nos fundos de pensão.

Além disso, critica-se a linha de privatização previdenciária chilena total pelo fato de haver redução do número de pessoas protegidas, causando uma reversão na tendência à universalização da proteção social.

Sobre a adoção de modelos de sistemas e estrangeiros de previdência, Sérgio Pinto Martins (Direito da Seguridade Social, 2000, p. 297) adota a seguinte postura: "não adianta querermos importar para o Brasil sistemas como o chileno ou outros. Se a Previdência Privada chilena fosse boa, os militares não se teriam excluidos de imediato do referido sistema"

Realmente, existe notória exclusão dos militares das Forças Armadas, e dos carabineros, fato que também configura um aspecto negativo chileno, pois fere a isonomia.

Outros fatores que causam insatisfação sobre o sistema previdenciário chileno são: baixa adesão dos trabalhadores autônomos e informais; grande número de pessoas sem condições de se aposentar (similares aos problemas do Brasil); e alto custo de administração dos fundos privados.

Então, o sistema previdenciário chileno possui os seus deméritos, não devendo figurar como paradigma irrefutável para os países da América do Sul. Se vem causando ainda insatisfação, após vinte anos de vigência, a confiabilidade do referido sistema fica deveras comprometida.

\section{Os 401(k) americanos}

O Plano Gerador de Benefícios Livres é típico das entidades abertas de Previdência Privada e Seguradoras brasileiras. Esse plano foi inspirado nos chamados 401(k) americanos, que concentram hoje U\$ 1,7 trilhão em investimentos nos EUA. Os planos de Previdência Privada mais populares nos EUA são justamente os 401(k) (número do instituto legal que permite a existência do plano) e o IRA (Individual 
Retirement Account). Os IRA são planos individuais de aposentadoria, enquanto que os 401(k) são planos oferecidos pelas empresas (coletivos). Esses planos têm características semelhantes às do Plano Gerador de Benefícios Livres brasileiro, tais como flexibilidade e ingerência do participante nas aplicações.

Os planos 401(k) surgiram com uma descoberta de R. Theodore Beuna, ex- consultor de planos de aposentadoria. Beuna descobriu, analisando o Ato de Reforma Tributária de 1978 (seção 401, parágrafo k), uma forma de poupança que beneficiasse a todos, dentro de um modelo de plano de aposentadoria.

Nesse tipo de plano, o empregado aplica parte do salário, sendo que a empresa pode ou não contribuir também.

O presidente George Walker Bush tomou posse no dia 20 de janeiro de. 2001, prometendo a privatizaçã̃o parcial da previdência social americana. A proposta notória de Bush consiste em disponibilizar $25 \%$ da contribuição previdenciária para aplicação na Previdência Privada (contas pessoais de aposentadoria). Essa é uma medida que só será possível diante dos abissais superávits alcançados pelos EUA nos últimos anos. Isso pela razão da diminuição conseqüente de $25 \%$ da arrecadação de contribuições previdenciárias, verba que fará falta no momento do pagamento dos benefícios.

Todavia, enquanto no nosso País os fundos de Previdência Privada aberta propiciam ao participante um benefício fiscal que permite o abatimento de até $12 \%$ de sua renda bruta tributável no ajuste da declaração anual do imposto de renda; nos EUA, as contribuições para os planos 401(k) e IRA podem ser deduzidas, integralmente, na declaração de IR. Esse exemplo poderia ser adotado pelo Brasil para incentivar o aumento da previdência complementar (e aliviar o encargo estatal da Previdência oficial). 


\section{Bibliografia}

MARTINS, Sérgio Pinto, Direito da Seguridade Social. Editora Atlas, 13 edição. São Paulo, 2000.

ORTEGA, Leonor, A Experiência Chilena na Previdência Social. (Escritório Comercial do Chile no Brasil). Obtido no site www.ufsc.br/latinidad/artigos/ prevchil.html. 